\title{
EKSPLORASI PERINTANG TEKSTIL DENGAN INSPIRASI VISUAL BATIK REMEKAN PADA PRODUK FASHION
}

\author{
Wahidiah Listianingrum ${ }^{1}$ \\ (Fakultas Industri Kreatif, Universitas Telkom Bandung, listy.listianingrum@gmail.com, \\ diahlistia@student.telkomuniveristy.ac.id, 085299311645) \\ Aldi Hendrawan ${ }^{2}$ \\ (Fakultas Industri Kreatif, Universitas Telkom Bandung, aldivalc@telkomuniversity.ac.id, 083820202077)
}

\begin{abstract}
The textile dyeing process is inseparable from the role of resist. Resisting in the coloring process functions as a medium to hold the dye to not soaked completely in the fabric that it can form the pattern. A few resist materials popular in the textile industry such as wax for Batik, rice paste for katazome, and cassava starch for adire eleko. Aside from starch, flour has the potential to resist dye. Flour is a material processed from starch that can be found in tubers or cereal plants. Besides aiming to find a suitable resist material from various types of flour, this research also aimed to resist innovation as raw material for the public using experimental methods through material exploration with Batik Remekan as inspiration and applied to kimono-style fashion product using soga tingi extracts and natural fiber fabric.
\end{abstract}

Keywords: resist, textile dye, flour, Batik Remekan.

\begin{abstract}
ABSTRAK
Proses pewarnaan tekstil tidak lepas dari peran perintang. Perintang dalam proses pewarnaan berfungsi sebagai media untuk menahan zat warna untuk meresap pada kain secara keseluruhan, sehingga motif bisa terbentuk. Hingga saat ini beberapa jenis perintang yang cukup populer dalam industri tekstil yaitu malam sebagai perintang batik, pasta beras pada teknik katazome dan pati singkong pada teknik adire eleko. Selain pati, bahan baku yang potensial digunakan sebagai perintang adalah tepung. Tepung merupakan hasil olahan pati yang ditemukan pada umbi - umbian atau tanaman sejenis serelia. Selain bertujuan untuk menemukan perintang yang cocok dari ragam jenis tepung. Penelitian ini juga bertujuan untuk memberikan inovasi bahan baku perintang kepada masyarakat yang dilakukan melalui metode eksperimental berupa eksplorasi dengan batik remekan sebagai inspirasi dan diaplikasikan pada produk fashion bergaya kimono menggunakan ekstrak soga tingi dan kain berserat alam.
\end{abstract}

Kata Kunci: perintang, pewarnaan tekstil, tepung, Batik Remekan.

\section{PENDAHULUAN}

Proses pewarnaan tekstil tidak lepas dari peran perintang. Penggunaan perintang pada teknik pewarnaan tekstil berfungsi untuk menahan atau menghalangi zat warna pada proses pewarnaan sehingga motif bisa terbentuk pada bagian yang terhalangi (ditutupi) oleh perintang. Bahan perintang yang digunakan pada proses pewarnaan tekstil cukup beragam seperti malam (lilin) yang digunakan pada proses pembatikan. Pati singkong yang digunakan pada teknik pembatikan Nigeria yaitu adire eleko serta 
campuran tepung ketan dan rice bran yang digunakan pada teknik katazome di Jepang (Fitriani, 2017). Berdasarkan penelitian sebelumnya milik Hanifah Fitriani (2017) yang berjudul "Pengolahan Kulit Umbi Singkong (Manihot utilissima) di Kawasan Kampung Adat Cirendeu Sebagai Bahan Baku Alternatif Perintang Warna Pada Kain" pati singkong dapat digunakan sebagai alternatif perintang warna karena memiliki daya rekat, kental, elastis, dan fleksibel. Selain singkong, pati dapat ditemukan pada umbi - umbian seperti ubi jalar dan talas, padi dan gandum. Pati tersusun atas rantai panjang glukosa yang terdiri atas amilopektin (zat pengental) dan amilosa (zat pelarut). Perbandingan amilosa dan amilopektin ini mempengaruhi sifat kelarutan dan tingkat gelatinisasi pati (Guilbert (1990) dalam Nisah (2017).

Di Indonesia, perintang yang digunakan pada poses pewarnaan tekstil sebagaian besar menggunakan lilin batik (malam). Padahal jika dilihat karakter dan fungsinya, material seperti pati dari singkong atau umbi - umbian lainnya yang diolah menjadi tepung juga dapat dijadikan sebagai perintang warna karena memiliki karakter dan fungsi yang sama dengan lilin batik (malam) yaitu merekat pada kain dan menghalangi pewarna pada bagian yang diinginkan. Berdasarkan uraian di atas, penelitian ini bertujuan untuk memberikan inovasi atau kebaruan pada bahan baku perintang dengan menemukan alternatif perintang warna alami. Inovasi dalam desain mengandung pengertian yaitu perubahan desain dalam segi material, bentuk (visual), fungsi dan teknologi untuk tujuan tertentu (Wicaksono, 2016). Dalam penelitian ini tujuan dari inovasi adalah untuk memberikan informasi kepada mahasiswa khususnya dalam bidang seni dan kriya bahwa perintang warna tekstil dapat ditemukan pada material yang memiliki karakter yang sama dengan malam (lilin), sehingga mampu menawarkan kebaruan dan orginalitas dalam teknik untuk pembuatan suatu karya. Selain perintang, penelitian ini juga menggunakan pewarna alami dan visual batik remekan. Batik remekan merupakan teknik pembuatan batik dengan cara meremas malam hasil tembokan yang menutupi kain hingga pecah. Lilin yang pecah tersebut akan dimasuki warna sehingga menghasilkan motif garis-garis seperti tanah yang pecah atau seperti kilat (Karsam, 2009). Motif remekan pada batik umumnya dibuat hanya untuk mengisi bidang yang luas pada kain batik tulis atau batik cap, sehingga dalam penelitian ini motif akan diolah agar bervariasi dengan memanfaatkan elemen desain seperti komposisi bentuk dan warna sebelum diaplikasikan pada produk busana ready-to-wear.

\section{METODE}

Metode yang digunakan pada penelitian ini merupakan metode ekperimental dengan pengumpulan data kualitatif berupa studi literatur, dan eksplorasi dengan rincian sebagai berikut :

1. Studi Literatur

Mengumpulkan data dari berbagai jurnal, tugas akhir dan tesis mengenai pengertian perintang, jenis - jenis perintang, ragam tepung dan kandungannya serta batik remekan.

\section{Eksplorasi}

Berupa pembuatan perintang menggunakan lima jenis tepung yaitu tepung ketan, tepung beras, tepung terigu, tepung tapioka, dan tepung maizena. Perintang dibuat dengan mencampurkan 200g tepung dan 400g air. Pengukuran kuantitas air dibuat dengan satuan gram agar lebih mudah dalam 
membandingkannya dengan kuantitas tepung. Cara ini terinspirasi dari penelitian Putry Malinda (2019) "Pengaruh Berat Tepung Tapioka Terhadap Hasil Jadi Motif Batik Tepung Pada Blouse" yang menggunakan satuan gram untuk menghitung kuantitas air dengan cara menuangkan air dalam wadah plastik sebelum diletakkan pada timbangan. Penelitian tersebut menggunakan tiga jenis takaran tepung yaitu 100g, 150g dan 200g dan air sebanyak 400g. Dari hasil penelitian yang dilakukan, hasil yang paling optimal yaitu dengan perbandingan 1:2 yaitu tepung $200 \mathrm{~g}$ dan air $400 \mathrm{~g}$. Perintang yang sudah tercampur rata kemudian dioleskan pada permukaan kain menggunakan perintang. Proses pengeringan memakan waktu selama 8 jam jika dibawah sinar matahari dan 14 jam jika tanpa sinar matahari (di dalam ruangan). Kemudian perintang yang sudah kering diremas hingga menghasilkan retakan. Retakan tersebut kemudian diwarnai menggunakan pewarna alami dari ekstrak soga tingi. Hasil dari pewarna yang masuk melalui celah retakan tersebutlah yang menghasilkan motif pada permukaan kain.

\section{STUDI LITERATUR}

\section{Perintang}

\subsection{Pengertian Perintang}

Perintang merupakan sebuah alat atau bahan yang digunakan sebagai media untuk merintangi atau menghalangi masuknya zat pewarna dalam proses pembatikan ataupun pewarnaan pada kain, sehingga bagian yang terhalangi oleh perintang dapat membentuk sebuah motif (Fitriani, 2017).

\section{2 Jenis - Jenis Perintang}

Beberapa jenis perintang yang digunakan pada proses pembatikan atau pewarnaan antara lain :

\section{a. Malam atau Lilin}

Malam atau batik merupakan cairan yang digunakan sebagai bahan perintang pada batik. Pengaplikasiannya bisa menggunakan canting atau stamp (cap) yang terbuat dari tembaga. Lilin batik dibuat dari campuran bahan organik atau sintetis yang terdiri tujuh macam, yaitu damar mata kucing (getah pohon Shorea Sp.), gondorukem (resina colophonium) yang merupakan residu destilasi getah pinus merkusii), kote (lilin lebah/beeswax), parafin (hasil samping dari pengolahan minyak mentah), microwax (hasil proses penyulingan minyak bumi sejenis parafin), kendal (lemak hewan), dan lilin bekas (Susanto (1980) dalam Haerudin \& Atika, 2018).

\section{b. Lumpur dan Tanah Liat}

Lumpur dan tanah liat juga dapat digunakan sebagai perintang warna. Di daerah India, tepatnya di daerah Gujarat, Rajasthan, dan Madhya Pradesh teknik pewarnaan dengan menggunakan lumpur dikenal dengan sebutan Dhabu Mud Resist Dyeing. Lumpur atau tanah liat dicampurkan dengan beberapa bahan lain seperti lime powder (calcium hydroxide, gum arabic, resin dan air kemudian dicelup dengan pewarna indigo (Streenivasam (1989) dalam Hann, 2005).

\section{c. Tali/Benang/Karet}

Menurut The Modern Textile Dictionary dalam (Widodo, 2013), tie-dye merupakan sebuat metode pencelupan atau pewarnaan yang menghasilkan motif atau bentuk di atas kain dengan cara mengikat kain menggunakan serat, tali atau benang sebelum dicelup atau diwarna. Di Jepang, tie- 
dye dikenal dengan istilah shibori yang berarti suatu variasi atau cara dalam menghiasi permukaan tekstil dengan cara dikuatkan sebelum diwarna. Shibori berasal dari kata shiboru yang berarti berakar, menjepit, dieratkan, dan ditekan. Kata "berakar" ditekankan pada cara pengerjaan kain yang indah, seperti permukaan dua dimensi dan bentuk dengan kesan tiga dimensi lipatan yang dikuatkan, dijahit, ditarik, dan dibelit dengan tali, sesuai lajur pola yang dikunci. Sedangkan di Indonesia teknik pembuatan motif dengan mengikat atau menjahit bagaian yang ingin dirintang dikenal dengan istilah teknik Ikat Celup.

\section{d. Es Batu}

Seiring berjalannya waktu, bahan - bahan yang digunakan sebagai perintang warna mulai beragam. Salah satunya merupakan bongkahan es batu yang juga bisa digunakan sebagai perintang warna. Dalam perkembangannya, penggunaan es batu sebagai perintang warna belum banyak digunakan karena cara pengaplikasiannya yang tidak mudah serta peluang keberhasilan yang rendah. Menurut Lynda Heines, salah satu fabric designer dan textile artist, metode pewarnaan dengan perintang es batu hanya bisa diaplikasikan dengan menggunakan jenis pewarna bubuk. Hal ini karena karakter es batu yang mudah mencair jika terkena panas atau udara yang kemudian akan melarutkan pewarna bubuk hingga membentuk motif pada permukaan kain.

\section{e. Pasta Tepung}

Beberapa jenis tepung dapat dijadikan sebagai perintang warna seperti penggunaan tepung beras ketan yang dijadikan sebagai pasta pada teknik katazome dan yuzen yang populer di Jepang sejak Periode Nara (710 794) (Wada (2002) dalam Puspitasari, 2018).
Pasta ini terbuat dari campuran tepung ketan (mochiko) dan rice bran (komon nuka) yang merupakan serbuk halus yang melapisi beras dalam biji padi ataupun gandum. Pasta yang dibuat dengan menggunakan 100\% beras ketan memiliki daya lekat yang sangat tinggi dan sifat pengeringan yang relatif lama, sehingga dalam teknik katazome atau yuzen, tepung beras akan ditambahkan rice bran sebelum dicampurkan dengan air. Pada teknik katazome, perintang akan diaplikasikan pada stensil sebelum melalui proses pewarnaan. Sedangkan pada teknik yuzen, pasta perintang dimasukkan pada sebuah tabung plastik (tube) yang kemudian diaplikasikan pada motif yang sudah dibuat pada kain. Ada juga penelitian yang menggunakan tepung tapioka, sebagai alternatif perintang warna pengganti malam atau lilin batik. karena memiliki memiliki karakter yang kental, lengket dan keras apabila kering. Dalam penelitian yang dilakukan oleh Tyas (2010) dalam Malinda, (2019) tepung tapioka dengan kadar air yang rendah mampu menghasilkan motif yang baik karena memiliki daya rekat yang baik.

\section{Tepung}

Tepung merupakan hasil olahan dari pati yang diperoleh dengan menghaluskan bagian tertentu dari suatu tumbuhan hingga berbentuk bubur yang kemudian diperas hingga tersisa ekstrak atau sarinya. Cairan kental yang tidak berwarna hingga putih keruh merupaka ekstrak yang nantinya dikeringkan. Hasil pengeringan ekstrak inilah yang menjadi tepung. Pati banyak ditemukan pada umbi - umbian seperti singkong, ubi jalar, dan talas serta tanaman sejenis padi dan gandum. 


\section{Batik Remekan}

Batik remekan adalah batik yang dibuat dengan cara meremas hasil tembokan malam hingga pecah. Lilin yang pecah tersebut akan kemasukkan warna sehingga menghasilkan warna garis-garis seperti tanah yang pecah atau seperti kilat (Karsam, 2009). Menurut Ansory (2011:13) dalam (Karsam, 2009) teknik pembuatan batik remekan ada dua yaitu :

a. Teknik retakan (cracks) serat kayu (Madura)

Batik dengan teknik retakan (cracks) serat kayu membentuk motif yang menyerupai tekstur serat kayu yang kemudian dipadukan dengan bentuk dan warna khas batik pesisir seperti motif bunga, daun dan sulur dengan warna merah, coklat, hijau, biru, dan kuning.

\section{b. Teknik retakan (cracks) untiran (Jawa Tengah)}

Batik dengan motif retakan (cracks) penuh yang dibuat dengan menggunakan warna orange dan coklat. Proses pembuatan batik remekan pada umumnya menggunakan malam (lilin batik) yang digabungkan dengan malam bekas lorodan. Namun menurut Siti Nur Sidah yang juga melakukan penelitian menggunakan malam carikan mengungkapan bahwa hasil jadi motif remekan menggunakan malam terlalu pecah. Hal ini disebabkan oleh parafin yang mudah encer, memiliki daya lekat kecil, mudah lepas dan meninggalkan sisa kotoran pada kain. Oleh karena itu diperlukan alternatif lain untuk membuat motif lebih kontras dan tidak terlalu pecah. Selain itu di Jawa Tengah, batik remekan hanya dibuat di atas kain katun yang memiliki daya serap paling baik (Sidah, 2015).

\section{HASIL DAN PEMBAHASAN}

\section{Eksplorasi Awal}

Eksplorasi awal bertujuan untuk menemukan komposisi bahan perintang yang paling mendekati visual dari batik remekan yang berupa motif retakan (cracks) pada kain. Eksplorasi menggunakan lima jenis tepung dengan perbandingan 100\% dan 50:50. Hasil eksplorasi yang paling optimal akan digunakan pada eksplorasi lanjutan.

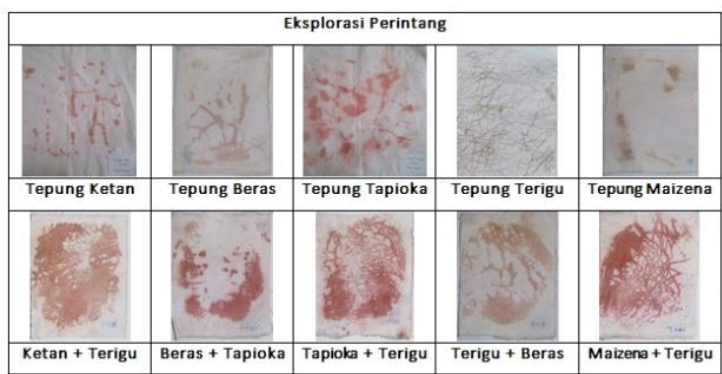

Tabel 1. Eksplorasi Perintang

Analisis:

Dari eksplorasi awal yang sudah dilakukan menggunakan lima jenis tepung, hasil yang paling optimal adalah menggunakan tepung terigu. Selain memberikan kenyamanan saat pengolesan karena tekstur yang ringan, hasil perintang jika kering juga menjadi keras dan mudah diremas untuk menghasilkan motif retakan (crack). Perintang terigu juga memiliki daya rekat yang baik sehigga motif bisa terbentuk dengan rapi dan tegas. Meskipun warnanya kurang jelas. Penggunaan perintang dengan tepung yang memiliki kandungan pelarut (amilosa) rendah cenderung lengket pada kuas dan celah hasil remasan (crack) mudah tertutup jika terkena pewarna. Perintang yang memiliki karakter seperti ini yaitu tepung ketan dan tapioka. Sedangkan untuk tepung maizena, hasil perintang yang mengering memiliki karakter yang lunak karena pati jagung 
yang bersifat hidrolik (memiliki daya serap air yang tinggi).

\section{Eksplorasi Lanjutan}

Pada eksplorasi ini perintang yang dipakai yaitu $100 \%$ tepung terigu. Pada tahap ini tujuan yang ingin dicapai adalah membuat motif lebih jelas dan kontras dengan eksplorasi mordan dan jenis kain. Eksplorasi Pre-Mordanting menggunakan metode cuci biasa, rebus tawas dan TRO dan eksplorasi Post-Mordanting menggunakan tunjung, kapur dan tawas. Pre-Mordanting bertujuan untuk menghilangkan semua jenis kotoran pada kain sehingga proses penyerapan lebih optimal. Sedangkan Post-Mordanting (Fiksasi) bertujuan untuk mengunci zat pewarna agar tidak mudah lepas sehingga memberikan hasil yang kontras dan tidak pudar (Mayliana, 2016). Kain yang digunakan merupakan kain berserat alam yaitu katun mori, katun rami, baby canvas dan canvas.

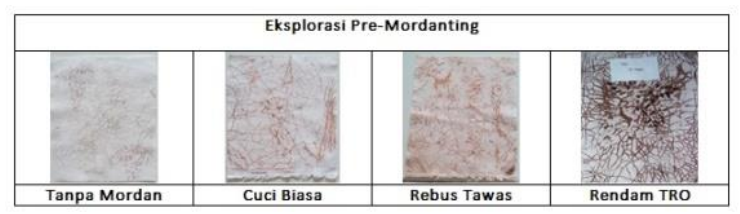

Tabel 2. Eksplorasi Pre-Mordanting

\section{Analisis:}

Dari ketiga metode pre-mordanting yang sudah dilakukan, hasil yang paling optimal adalah menggunakan TRO (Turkish Red Oil). Meskipun pre-mordanting dengan metode perebusan dengan tawas juga bisa mengasilkan motif yang baik, namun kain menjadi berwarna orange dan kurang kontras.

Setelah mendapatkan hasil yang optimal dari eksplorasi pre-mordanting menggunakan TRO. Selanjutnya eksplorasi akan dilakukan adalah perendaman TRO dengan tiga jenis waktu yang berbeda mulai dari 3 menit, 10 menit dan 30 menit. Eksplorasi ini bertujuan untuk melihat perbandingan motif yang dihasilkan jika menggunakan waktu yang berbeda - beda.

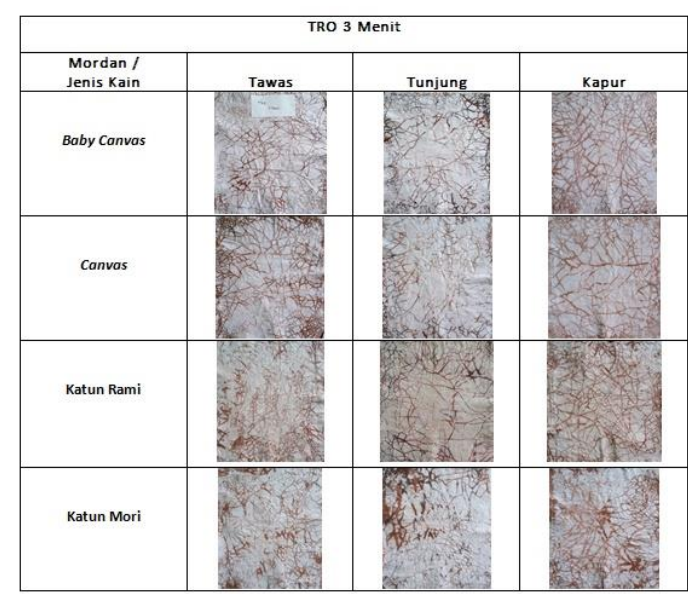

Tabel 3. Eksplorasi TRO 3 Menit

\section{Analisis:}

Hasil pre-mordanting dengan menggunakan TRO selama 3 menit motif cracking yang muncul sebagaian besar hanya yang besar saja. Motif ini diperoleh dengan mengoleskan adonan tepung terigu secara tebal dan merata pada permukaan kain. Untuk permukaan kain dengan olesan tipis, motif cracking masih tidak terlihat atau kurang jelas. Pewarna belum bisa menembus kain yang dirintang dengan adonan tepung terigu.

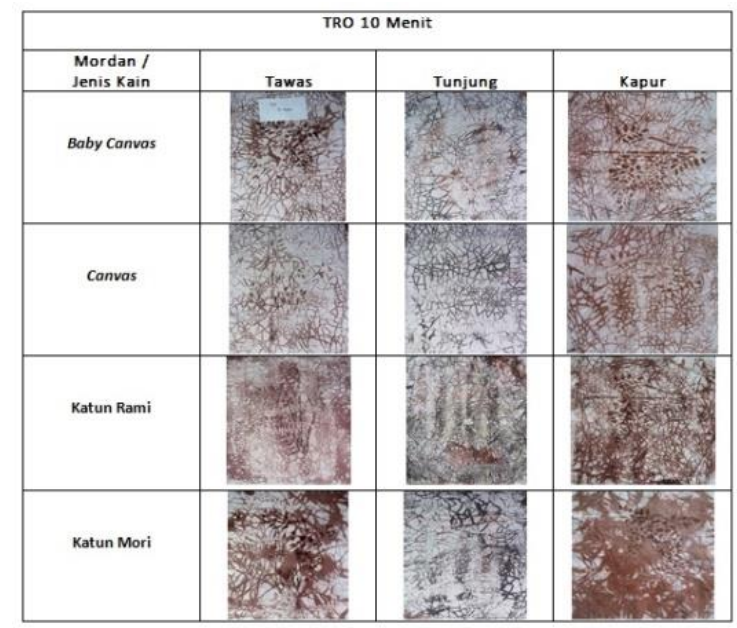

Tabel 4. Eksplorasi TRO 10 Menit 


\section{Analisis:}

Hasil eksplorasi dengan pre-mordanting TRO 10 menit menghasilkan kain dengan motif yang jelas dan banyak. Jika pada eksperimen dengan TRO 3 menit motif kecil tidak terlihat, maka di eksperimen dengan TRO 10 menit, motif kecil sudah mulai terlihat jelas. Namun kain dengan karakteristik tipis seperti katun mori dan katun rami, penyerarapan warnya terlalu liar. Meskipun kain sudah diberi perintang namun warna masih bisa terserap pada kain. Sehingga motif yang dihasilkan pada percobaan TRO 10 menit terlalu banyak dan penuh.

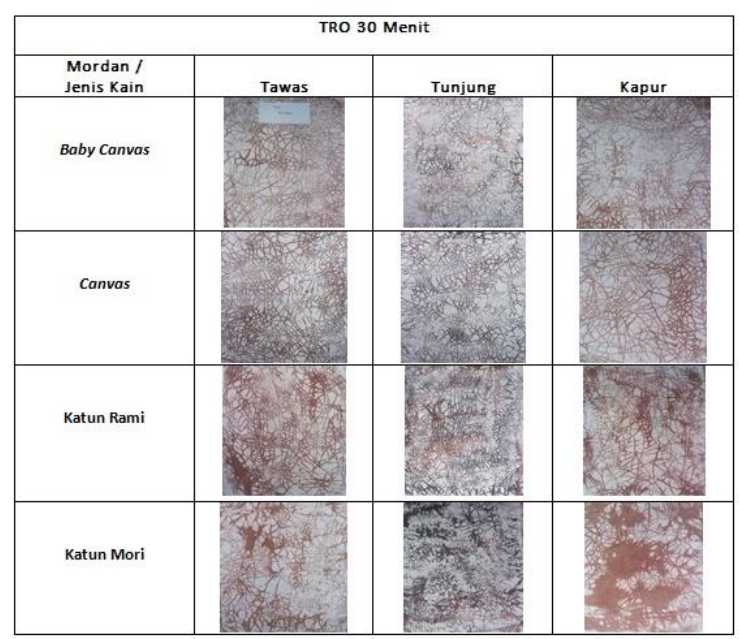

Tabel 5. Eksplorasi TRO 30 Menit

\section{Analisis :}

Hasil eksplorasi pre-mordanting TRO selama 30 menit menghasilkan motif dengan gurat yang sangat jelas dan penuh. Sama seperti ekplorasi dengan TRO 10 menit jika crack kecil tetap bisa terlihat pada kain. Namun bedanya pada eksplorasi TRO 30 menit, beberapa kain seperti katun rami dan katun mori menjadi lebih kotor dan menjadi ikut terwarna. Hal ini karena daya serap kain terhadap pewarna sangat tinggi sehingga, selain penyerapan warna dari celah perintang, kain juga menyerap warna ketika pada proses menghilangkan perintang (lorod).

\section{Eksplorasi Akhir}

Dari hasil eksplorasi lanjutan Pre-Mordanting menggunakan TRO 30 menit lebih efektif dari waktu yang lain (3 menit dan 10 menit) karena kain tidak perlu dibagi untuk menandai bagian yang ingin di atur. Motif juga lebih mudah diatur meski kain dicelup seluruhnya pada 1 jenis waktu TRO. Kain yang terpilih yaitu baby canvas karena mampu memberikan hasil yang rapi dan bersih. Kemusian fiksator yang dipilih yaitu tunjung karena mampu memberikan warna yang paling kontras sehingga motif retakan yang berupa garis - garis tipis bisa lebih terlihat jelas. Hasil eksplorasi yang terpilih diaplikasikan pada produk fashion ready-to-wear bergaya kimono. Hal ini karena kimon memiliki pola yang sederhana, tanpa aplikasi tambahan seperti saku, kupnat, ruffle atau bentuk aplikatif lainnya. Sehingga value produk berupa motif, pewarna kan kain berserat alam bisa lebih terlihat jelas.

\section{Hasil Produk}

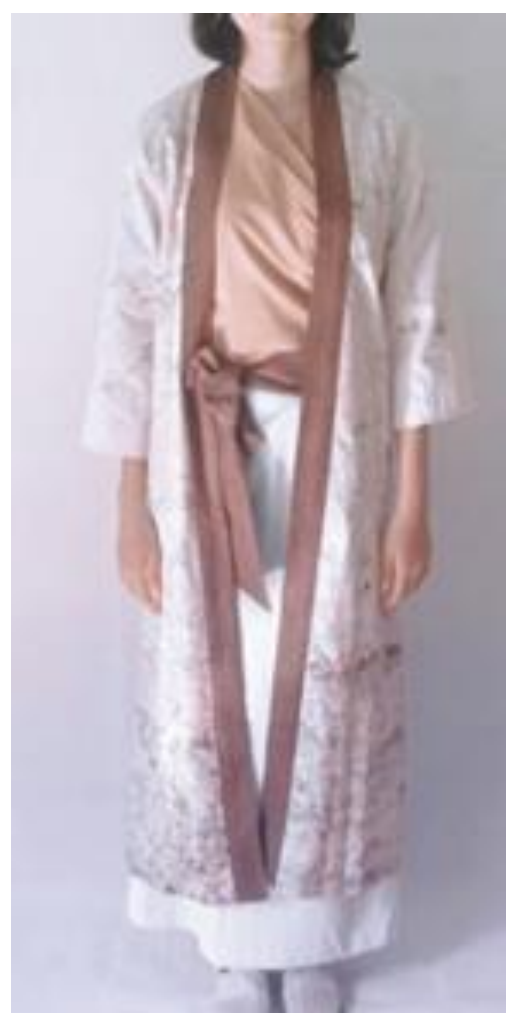




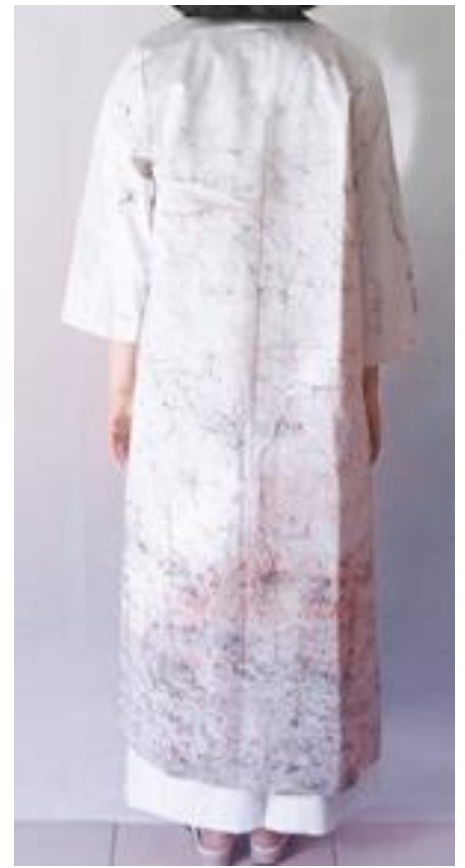

Gambar 1. Tampak Depan - Belakang

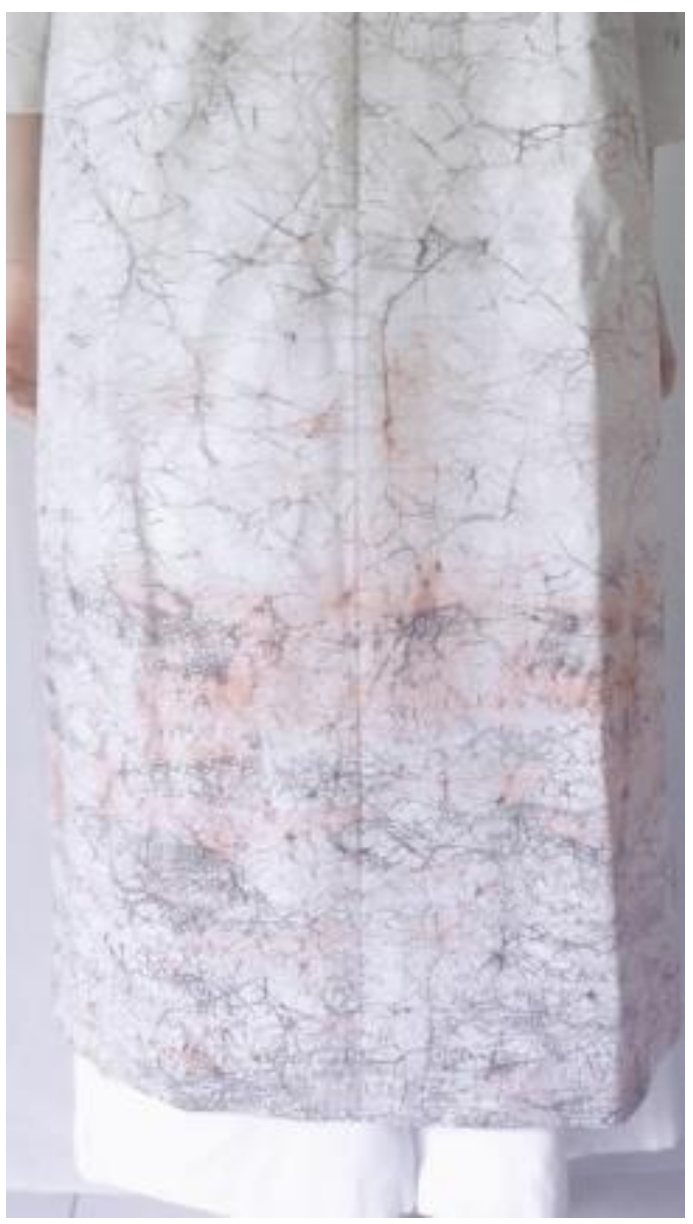

Gambar 2. Detail Motif
PENUTUP

Kesimpulan

Penggunaan perintang tekstil menggunakan lilin batik (malam) merupakan hal yang umum di Indonesia. Padahal Indonesia kaya akan sumber daya alam yang berpotensi untuk dimanfaatkan sebagai perintang jika dilihat karakter dan fungsinya, seperti pati dari tanaman sejenis umbi - umbian dan serelia. Salah satu olahan pati dari umbi - umbian yang dapat digunakan sebagai perintang warna yaitu tepung. Tepung memiliki karakter yang hampir sama dengan lilin yaitu mampu merekat pada kain dan menghalangi motif dari zat pewarna ketika proses pencelupan atau pewarnaan kain.

\section{Saran}

Semua jenis tepung pada dasarnya dapat digunakan sebagai alternatif perintang. Namun perlu eksplorasi terhadap ukuran air sebagai campuran untuk mendapatkan adonan yang ideal. Hal ini karena setiap jenis tepung memiliki karakter dan daya serap yang berbedabeda.

\section{DAFTAR PUSTAKA}

Fitriani, H. (2017). Pengolahan Kulit Umbi Singkong (Manihot utilissima) di Kawasan Kampung Adat Cirendeu Sebagai Bahan Baku Alternatif Perintang Warna Pada Kain. 1-5. Retrieved from https://openlibrary.telkomuniversity.ac.id /home/catalog/id/137253/slug/pengolah an-kulit-umbi-singkong-manihotutilissima-di-kawasan-kampung-adatcireundeu-sebagai-bahan-baku-alternatifperintang-warna-pada-kain.html

Haerudin, A., \& Atika, V. (2018). Komposisi Lilin Batik (Malam) Biron Untuk Batik Warna Alam Pada Kain Katun dan Sutera. Jurnal Dinamika Dan Kerajinan Batik, 35, 25-32. 
https://doi.org/10.1017/CBO9781107415 324.004

Hann, M. A. (2005). Wax/Paste Resist

Techniques Regional Variants. In D. Holdcroft (Ed.), Patterns of Culture Techniques of Decoration and Coloration. England: University of Leeds International Textiles Archive (ULITA).

Karsam. (2009). Kesalahan-Kesalahan Dalam Pemahaman Motif Batik Dan Aplikasinya Pada Baju. Seminar Nasional Sistem \& Teknologi Informasi (SNASTI). Retrieved from

http://repository.dinamika.ac.id/id/eprint $/ 451$

Malinda, P. (2019). Pengaruh Berat Tepung Tapioka Terhadap Hasil Jadi Motif Batik Tepung (Flour Paste batik) Pada blus (Blouse). Jurnal Tata Busana, 8(1), 19-23. Mayliana, E. (2016). Pengaruh Lama Waktu Mordanting Terhadap Ketuaan Warna dan Kekuatan Tarik Kain Mori dalam Proses Pewarnaan dengan Zat Pewarna Sabut Kelapa. Corak Jurnal Seni Kriya, 5(1), 9-15. https://doi.org/https://doi.org/10.24821/ corak.v5i1.2373

Nisah, K. (2017). Study Pengaruh Kandungan Amilosa Dan Amilopektin Umbi-Umbian Terhadap Karakteristik Fisik Plastik Biodegradable Dengan Plastizicer Gliserol. Jurnal Biotik, 5(2), 106-113.

Puspitasari, S. I. (2018). Pengolahan Motif Dengan Inspirasi Teknik Katazome (Universitas Telkom). https://doi.org/10.1017/CBO9781107415 324.004

Sidah, S. N. (2015). Studi Komparasi Hasil Jadi Batik Remekan Menggunakan Malam Carikan dengan Parafin pada Kain Katun. Jurnal Tata, 04(03), 8-15. Retrieved from https://jurnalmahasiswa.unesa.ac.id/inde x.php/jurnal-tata-

busana/article/view/12153

Wicaksono, A. (2016). Potensi Pengembangan Inovasi Desain Produk Kriya KUKM Indonesia di Era Industri Kreatif. Corak Jurnal Seni Kriya, 5(2), 103-112. https://doi.org/https://doi.org/10.24821/ corak.v5i2.2380

Widodo, S. T. (2013). Kriya Tekstil Tie-Dye (Ikat Celup): Sebuah Media Eksplorasi Estetis Yang Populer. Corak, 1(2). https://doi.org/10.24821/corak.v1i2.347 